\title{
Bench Study of a New Device to Display and Maintain Stable Artificial Airway Cuff Pressure
}

\author{
William R Howard MBA RRT
}

\begin{abstract}
BACKGROUND: Artificial airway cuff pressure should be maintained within a narrow range. Excessive cuff pressure presents a risk of tracheal damage and stenosis. Insufficient cuff pressure adds the risk of secretion leak past the cuff, tidal-volume leakage, and accidental extubation. The available cuff-inflation devices do not address these problems. OBJECTIVE: In the laboratory I developed and evaluated a new cuff-inflation device that continuously displays the cuff pressure and maintains stable cuff pressure. METHODS: The cuff-inflation device evaluation included: test the manometer accuracy; compare the displayed pressure to the pressure delivered to the pilot balloon; determine the device's response to cuff-pressure changes with the addition of $5 \mathrm{~mL}$ or $10 \mathrm{~mL}$ of air after achieving a $30 \mathrm{~cm} \mathrm{H}_{2} \mathrm{O}$ baseline; measure the $\mathrm{V}_{\mathrm{T}}$ leak in an intubated artificial trachea by comparing the device results to benchmark measurements; and determine the stability of baseline cuff pressure during routine cuff checks. RESULTS: The mean \pm SD bias and precision of device's display, compared to the calibration analyzer, was $1.3 \pm 2.6 \mathrm{~cm} \mathrm{H}_{2} \mathrm{O}$. The pressure delivered by the cuff-inflation device's gas-sampling line to the pilot balloon was equal to the pressure displayed by the cuff-inflation device. With the cuff-inflation device the cuff pressure was unchanged, compared to baseline, after adding $5 \mathrm{~mL}$ or $10 \mathrm{~mL}$ of air. With 2 current cuff methods, cuff pressure increased to means exceeding $160 \mathrm{~cm} \mathrm{H}_{2} \mathrm{O}$ and $300 \mathrm{~cm} \mathrm{H}_{2} \mathrm{O}$, respectively. Compared to the benchmark, the difference in exhaled $V_{T}$ mean $\pm S D$ bias and precision were: cuff-inflation device $1.4 \pm 4.8 \mathrm{~mL}$, and syringe-inflation method $2.4 \pm 6.2 \mathrm{~mL}$. Representing a single cuff pressure check, disconnecting the endotracheal-tube pilot balloon from the cuff-inflation device's gas-sampling line and then reconnecting it had no effect on baseline cuff pressure at 2 seconds or 60 seconds. CONCLUSIONS: The cuff-inflation device demonstrated possible improvements over available cuff-inflation devices and cuff-pressure-control methods. Key words: artificial airway; cuff pressure; tracheal damage; stenosis; tidal volume; accidental extubation. [Respir Care 2011;56(10):1506-1513. (c) 2011 Daedalus Enterprises]
\end{abstract}

\section{Introduction}

It is recommended to maintain artificial-airway cuff pressure within $20-30 \mathrm{~cm} \mathrm{H}_{2} \mathrm{O} .{ }^{1-6}$ Excessive cuff inflation is a recognized risk factor for tracheal injury and stenosis. ${ }^{7}$

Mr Howard is affiliated with the Department of Respiratory Care, Tufts Medical Center, Boston, Massachusetts.

The author has disclosed no conflicts of interest.

Correspondence: William R Howard MBA RRT, Department of Respiratory Care, Tufts Medical Center, 800 Washington Street, Box 785, Boston MA 02111. E-mail: whoward@ tuftsmedicalcenter.org.

DOI: $10.4187 /$ respcare.00961
Insufficient cuff pressure can increase the leakage of subglottic secretions past the cuff, contribute to air leak, and increase the risk of accidental extubation. ${ }^{8-13}$ Techniques such as palpation of the pilot balloon or performing routine checks using the minimal occlusive volume technique have not provided protection against these risk factors. ${ }^{14-20}$

See the Related Editorial on Page 1625

Cuff pressure must be monitored to ensure that the pressure remains within the recommended range. ${ }^{21-29}$ Unfortunately, the existing techniques and devices for monitoring cuff pressure are inadequate and do not lessen the risk factors associated with artificial airways. ${ }^{30,31}$ 


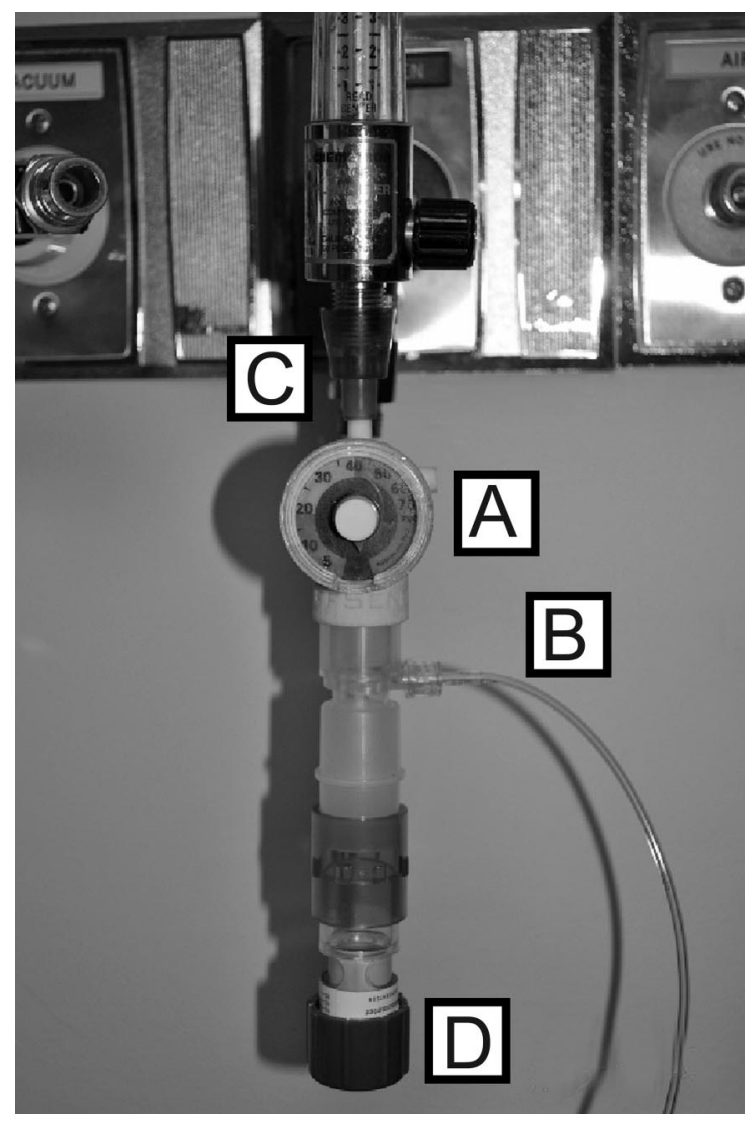

Fig. 1. Artificial airway cuff-inflation device. A: Manometer for continuous display of cuff pressure. B: Gas-sampling line, which connects the cuff-inflation device to the cuff pilot balloon. C: Connection between the cuff-inflation device and the flow-meter outlet. D: Pressure-relief valve adjustment for setting the cuff pressure.

I designed a new device to continuously measure and display cuff pressure, and we evaluated the device's effectiveness in the laboratory. The cuff-inflation device is designed to comply with the American Thoracic Society's and Infectious Disease Society's ventilator-associated pneumonia level-II recommendation for maintaining cuff pressure above $20 \mathrm{~cm} \mathrm{H}_{2} \mathrm{O} .{ }^{32}$

\section{Methods}

Fig. 1 shows the new cuff-inflation device that was evaluated. The applied pressure from the cuff-inflation device is adjustable, and in the tested configuration it has an operational range of $0-80 \mathrm{~cm} \mathrm{H}_{2} \mathrm{O}$. The device attaches to a standard flow meter, and the flow from it is directed through a gas-sampling line to the artificial airway's pilot balloon. The cuff-inflation device is intended to apply a selectable and consistent pressure to the cuff, without cuffpressure fluctuation, and to accurately display the cuff pressure.
The device consists of a disposable pressure manometer and a modified, adjustable pressure-relief valve (Ventlab, Mocksville, North Carolina) that has a $22 \times 22-\mathrm{mm}$ innerdiameter connector (Airlife, Cardinal Health, Dublin, Ohio). The standard adjustable PEEP valve was modified from the original $0-20 \mathrm{~cm} \mathrm{H}_{2} \mathrm{O}$ range by adding 3 more springs, which increased the cuff-inflation device's pressure limit to $80 \mathrm{~cm} \mathrm{H}_{2} \mathrm{O}$ for this study. The cuff-inflation device also uses a gas-sampling connector (Smiths Medical North America, Dublin, Ohio), a 3-m length of a male-luer to male-luer gas sampling line (Smiths Medical North America, Dublin, Ohio), and an oxygen tubing connector (Salter Labs, Arvin, California).

\section{Test Setup}

The cuff-inflation device was attached to the DiameterIndex Safety System outlet of a standard 0-15 L/min, back-pressure-compensated, oxygen flow meter (Precision Medical, Northampton, Pennsylvania). One end of the gassampling line was attached to the gas-sampling port of the cuff-inflation device. The male luer connection on the opposite end of the gas-sampling line was attached to a series of 3-way stopcocks (Fig. 2A). The assembly was used as a connection hub for the cuff-inflation device, the artificial airway pilot balloon, a cuff-inflation syringe, a standard analog pressure gauge (DHD Healthcare, Canastota, New York), and a pressure calibration analyzer (DPM2Plus, Fluke Biomedical, Everett, Washington). The stopcocks were turned, as determined by the tests described below, so that the pilot balloon, the cuff-inflation device gassampling line, the syringe-pressure gauge, and the pressure analyzer were in open communication.

A 15-cm length of standard 22-mm inner-diameter aerosol hose was used as an artificial trachea. Three artificial airways were used: a 9.0-mm inner-diameter (12.2-mm outer-diameter) endotracheal tube (ETT) (Sheridan, Teleflex Medical, Research Triangle Park, North Carolina); a 9.0-mm inner-diameter (12.6-mm outer-diameter) ETT (Microcuff, Kimberly-Clark Health Care, Roswell, Georgia); and a 9.0-mm inner-diameter (12.6-mm outer-diameter) cuffed tracheostomy tube with disposable inner cannula (Sims Portex, Keene, New Hampshire). The artificial trachea was intubated with these water-soluble lubricated airways. The opposite end of the artificial trachea was fitted with a male-male connector attached to a test lung $\left(\mathrm{V}_{\mathrm{T}}-2\right.$ Bio-Tek Instruments, Winooski, Vermont). The ETT was connected to a ventilator (Puritan Bennett 840, Covidien-Nellcor, Boulder, Colorado) with a standard adult patient circuit.

\section{Test 1}

Part 1 of Test 1 compared the pressure in the cuffinflation device to the pressure at the end of the 3-m gas- 
A
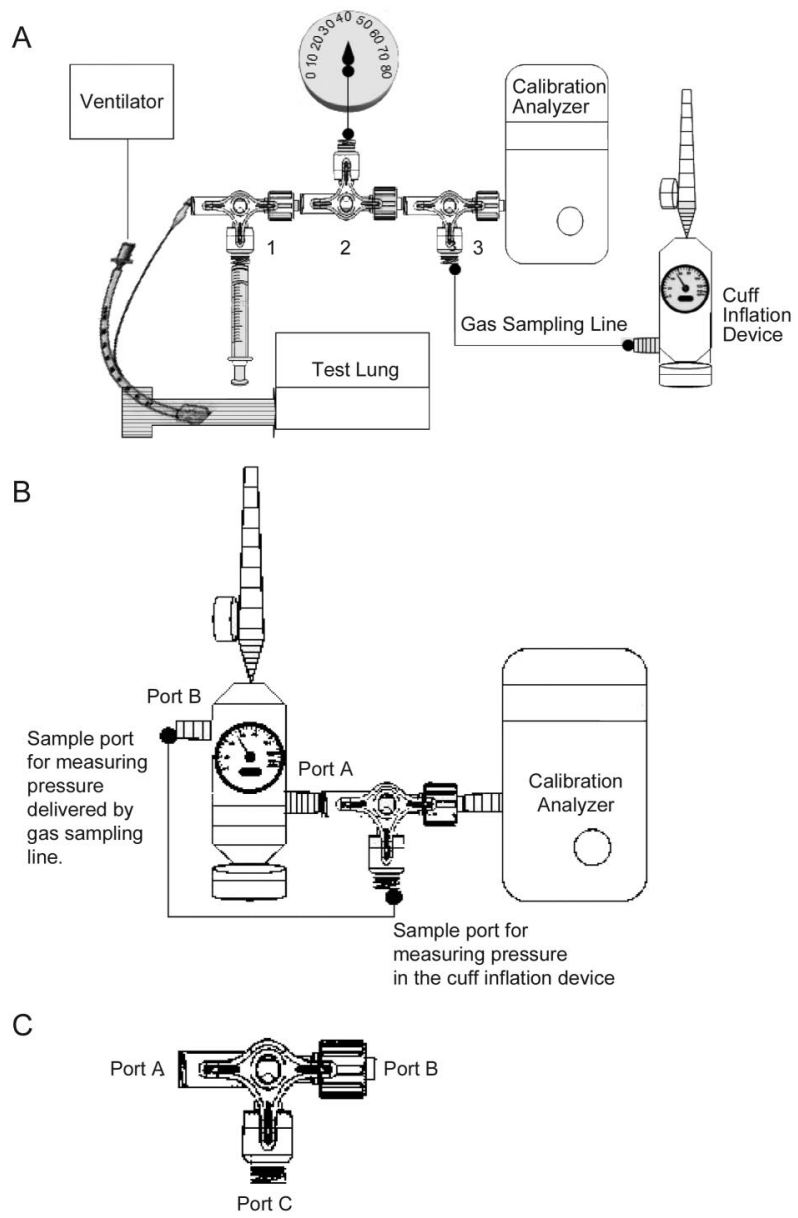

Fig. 2. A: Cuff-inflation device test setup, which includes cuff pilot balloon, cuff-inflation syringe, standard analog pressure gauge, and pressure-calibration analyzer. A syringe and cuff inflator was attached to the endotracheal tube via a stopcock in the check valve at the end of the pilot tube. B: Setup for Part 1 of Test 1 . The cuff-inflation device and calibration analyzer were connected via a single stopcock. The cuff-inflation device stopcock was adjusted Port A or Port B communication with the calibration analyzer. This test measured pressure within the cuff-inflation device, and compared this to the pressure delivered at the end of the gas-sampling line. C: The 3 stopcock ports used in the test hub. Port $A$ and Port B are open while Port C is closed.

sampling line that was attached to the test hub. This comparison was to determine if the cuff-inflation device's displayed pressure was a reliable indicator of the applied cuff pressure.

Part 2 of Test 1 compared the cuff-inflation device's pressure-gauge measurement to the measurement from the calibration analyzer, to establish the accuracy of the manometer.

For Test 1 only, the cuff-inflation device and the calibration analyzer were connected via a single stopcock (see Fig. 2B). In Test 1, Part 1, the stopcock was adjusted to open Port A of the cuff-inflation device and to close Port B. This provided a direct communication between the calibration analyzer and the cuff-inflation device. The cuff-inflation device was attached to the flow meter, which was set to deliver a gas flow of $2 \mathrm{~L} / \mathrm{min}$. The cuff-inflation device's pressure-relief valve was adjusted sequentially to calibration-analyzer readings of 20,30,40,50, and $60 \mathrm{~cm} \mathrm{H}_{2} \mathrm{O}$. The cuff-inflation device pressures were measured with the calibration analyzer and recorded at each level. All of the pressure measurements were taken from the calibration analyzer, to avoid intra-device error, and recorded in a spreadsheet (Analysis ToolPak, Excel SP-2 professional edition, Microsoft, Redmond, Washington).

The stopcocks were then adjusted with Port B of the cuff-inflation device open to the calibration analyzer and closed to Port A. The same cuff-inflation-device adjustments were repeated to measure the pressure delivered by the gas-sampling line. These data were also recorded in the spreadsheet.

In Part 2 of Test 1, and for the remainder of the evaluation, the cuff-inflation device and calibration analyzer were reconnected to the main test hub. The 3 stopcocks were adjusted with Ports A and B open (see Fig. 2C), to establish communication between the cuff-inflation device, calibration analyzer, and pilot balloon. PEEP of $5 \mathrm{~cm} \mathrm{H}_{2} \mathrm{O}$ was applied. The cuff-inflation device was sequentially adjusted to its display value of $20,30,40,50$, and $60 \mathrm{~cm} \mathrm{H}_{2} \mathrm{O}$ at test-lung compliance settings of 10, 20, 30, 40, and $50 \mathrm{~mL} / \mathrm{cm} \mathrm{H}_{2} \mathrm{O}$. These displayed cuff-inflation-device values and the simultaneously measured calibration-analyzer values were recorded in the spreadsheet. This test was repeated at $10 \mathrm{~cm} \mathrm{H}_{2} \mathrm{O}$ and repeated with a second cuffinflation device, which produced 100 cuff-pressure measurements.

\section{Test 2}

Test 2 was designed to determine the cuff-inflation device's response to cuff-pressure changes that occur from the diffusion of $\mathrm{N}_{2} \mathrm{O}$ into the cuff during intraoperative administration, and the device's response to cuff-pressure changes during a patient's daily activities (eg, movement, suctioning, and coughing).

Part 1 of Test 2 evaluated the cuff-inflation device's response to the addition of air injected into the ETT cuff, after achieving an initial baseline cuff pressure of $30 \mathrm{~cm} \mathrm{H}_{2} \mathrm{O}$. End-expiratory pressure of $5 \mathrm{~cm} \mathrm{H}_{2} \mathrm{O}$ was applied to the Teleflex Medical ETT. The cuff-inflation device was adjusted sequentially until the calibration analyzer displayed values of 20,30,40,50, and $60 \mathrm{~cm} \mathrm{H}_{2} \mathrm{O}$ at the test-lung compliance settings of 10,20,30,40, and $50 \mathrm{~mL} / \mathrm{cm} \mathrm{H}_{2} \mathrm{O}$. Twenty-five $\mathrm{mL}$ of air was injected from the syringe into the pilot balloon (see Fig. 2A) over a 


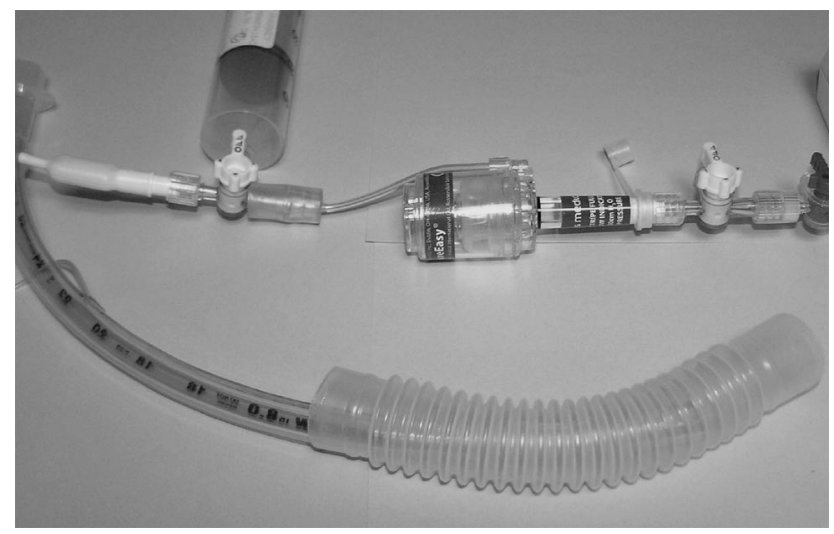

Fig. 3. The PressureEasy device was added between the pilot balloon and the test hub. It was evaluated for the effect on cuff pressure after adding $5 \mathrm{~mL}$ and $10 \mathrm{~mL}$ of air to the cuff after baseline inflation.

60-second period. After a 60-second period of stabilization, the pressure measurements from the calibration analyzer were recorded. This process was repeated at an endexpiratory pressure of $10 \mathrm{~cm} \mathrm{H}_{2} \mathrm{O}$, and with the second cuff-inflation device. The calibration analyzer measurements were recorded for comparison at each pressure.

Part 2 of Test 2 was designed to compare the performance of 2 other cuff-pressure management methods to that of the cuff-inflation device. Additional volumes of air were injected into the cuff after an initial baseline cuff pressure of $30 \mathrm{~cm} \mathrm{H}_{2} \mathrm{O}$ was established. Baseline cuff pressure of $30 \mathrm{~cm} \mathrm{H}_{2} \mathrm{O}$ was initially achieved with 3 types of cuff-pressure management methods: the cuff-inflation device, syringe inflation, and a commercially available cuff-pressure controller (PressureEasy, Medex/Smith's Medical, St Paul, Minnesota). The response of adding further amounts of air into the cuff after initial baseline was established was then compared.

The tracheal model was intubated sequentially with the 3 artificial airways. The cuff was inflated until a calibration-analyzer cuff-pressure reading of $30 \mathrm{~cm} \mathrm{H}_{2} \mathrm{O}$ was obtained. This was followed by injecting $5 \mathrm{~mL}$ and then $10 \mathrm{~mL}$ of air sequentially into the cuff through the test hub assembly.

There was one exception in the set-up with the PressureEasy device. It was connected, per the manufacturer's recommendations, between the pilot balloon and the inflation syringe (Fig. 3). The PressureEasy was inflated the same as the other 2 methods, through the test hub assembly. Sufficient air was initially injected until the PressureEasy visual indicator was raised to the recommended mid-point position, which represented the initial baseline for the PressureEasy. An additional $5 \mathrm{~mL}$ and then $10 \mathrm{~mL}$ of air was then injected sequentially from the syringe into the pilot balloon, through the attached stopcock assembly. Sixty seconds after each addition of air, the cuff-pressure measurements displayed on the calibration analyzer were recorded for comparison to the baseline cuff pressure.

\section{Test 3}

Test 3 was designed to evaluate the cuff-inflation device's ability to maintain a tracheal-cuff seal at various levels of compliance and PEEP. The integrity of the tracheal-cuff seal was deemed effective if the exhaled $V_{T}$ measurement was no less than the benchmark measurement, which was with the patient circuit connected directly to the test lung, with the artificial airway and artificial trachea removed. The cuff-inflation device and syringe-inflation method of sealing the cuff against the artificial trachea were evaluated and compared to the benchmark exhaled $V_{T}$.

The cuff-inflation device was evaluated while mechanically ventilating the test lung (see Fig. 2A), with both types of cuffed ETT and the tracheostomy tube. The artificial airways were coated with a water-soluble lubricant (Johnson \& Johnson, New Brunswick, New Jersey) prior to insertion into the artificial trachea. The test-lung compliance was sequentially adjusted to $10,20,30,40$, and $50 \mathrm{~mL} / \mathrm{cm} \mathrm{H}_{2} \mathrm{O}$. At each compliance the ventilator was set to $\mathrm{V}_{\mathrm{T}}$ of $500,600,700$, and $800 \mathrm{~mL}$, respiratory rate of 15 breaths/min, PEEP of $5 \mathrm{~cm} \mathrm{H}_{2} \mathrm{O}$ and $10 \mathrm{~cm} \mathrm{H}_{2} \mathrm{O}$, and a peak flow rate to maintain the inspiratory-expiratory ratio at 1:2. The syringe and analog pressure gauge were closed to the hub, and Stopcock 3 was opened to allow the cuff-inflation device to inflate the cuff. The cuff-inflation device was adjusted and set to approximately $5 \mathrm{~cm} \mathrm{H}_{2} \mathrm{O}$ above the peak airway pressure.

With the syringe-inflation method, Stopcock 3 of Port A (see Fig. 2A) was turned off to Stopcocks 1 and 2, which isolated the cuff-inflation device and calibration analyzer from the test hub. Stopcocks 1 and 2 were open to the syringe, pilot balloon, and the analog pressure gauge, which allowed air injection from the syringe into the cuff. Approximately $5 \mathrm{~cm} \mathrm{H}_{2} \mathrm{O}$ above the peak airway pressure was targeted at each setting and measured with the analog gauge. After 30 breaths were delivered, the next 10-breath exhaled $V_{T}$ average from the ventilator's measurement display was recorded. The step-by-step process, as described in the first phase of this test, was repeated, and the measurements were recorded in the spreadsheet.

The artificial trachea was then removed and the patient circuit was connected directly to the test lung. The first phase of this test was repeated to represent the benchmark of $\mathrm{V}_{\mathrm{T}}$, and these measurements were recorded.

Test 3 produced 120 exhaled $V_{T}$ measurements each from the syringe-inflation method and the cuff-inflation device. 
These measurements were compared to the $\mathrm{V}_{\mathrm{T}}$ measurements from the direct circuit connection to the test lung.

\section{Test 4}

Test 4 was designed to determine whether the cuffinflation device would maintain a baseline cuff pressure if used intermittently for routine checks. The baseline cuff pressure was compared to the cuff pressure that resulted after a single disconnection and reconnection of the cuffinflation device to the pilot balloon.

With 0 PEEP, the cuffs were sequentially inflated to 20 , $30,40,50$, and $60 \mathrm{~cm} \mathrm{H}_{2} \mathrm{O}$. The test-lung compliance was also adjusted in sequence to $10,20,30,40$, and $50 \mathrm{~mL} /$ $\mathrm{cm} \mathrm{H}_{2} \mathrm{O}$. The stopcocks were open to allow communication between the pilot balloon, the calibration analyzer, and the cuff-inflation device. After a 60 -second period of stabilization at each setting, the ETT pilot balloon was disconnected. After another 60 seconds it was reattached to the test hub and the cuff pressure was recorded at $2 \mathrm{sec}-$ onds and 60 seconds. These same tests were repeated with PEEP of $5 \mathrm{~cm} \mathrm{H}_{2} \mathrm{O}$ and $10 \mathrm{~cm} \mathrm{H}_{2} \mathrm{O}$. A total of 150 measurements were recorded.

\section{Statistical Analysis}

The data from Test 1 and Test 3 were analyzed with limits-of-agreement analysis. ${ }^{33}$ In Test 1 , bias was calculated as the mean difference between the cuff-pressure measurement from the calibration analyzer and that from the cuff-inflation device. Precision was calculated as the range included between \pm 2 standard deviations from the mean difference. In Test 2, the cuff-pressure measurements were averaged and compared to actual cuff pressure with the calibration analyzer at 20, 30, 40, 50, and $60 \mathrm{~cm} \mathrm{H}_{2} \mathrm{O}$, with a 1-sample $t$ test.

In Test 3, bias was calculated as the mean difference in measured exhaled $\mathrm{V}_{\mathrm{T}}$ between the direct ventilator-circuit connection to the test lung and the measured exhaled $\mathrm{V}_{\mathrm{T}}$ after inflating the cuffs with the cuff-inflation device or syringe method. Precision was taken as the range included between \pm 2 standard deviations from the mean difference.

In Test 4 , the cuff pressure measured at 2 seconds and 60 seconds after reconnection was averaged at the 3 PEEP and test-lung compliance settings. This was compared to the respective baseline cuff pressure of 20,30, 40, 50, and $60 \mathrm{~cm} \mathrm{H}_{2} \mathrm{O}$, which were measured with the calibration analyzer, with a 1 -sample $t$ test.

All descriptive statistics were calculated with the spreadsheet software. Differences were considered statistically significant when $P<.05$.

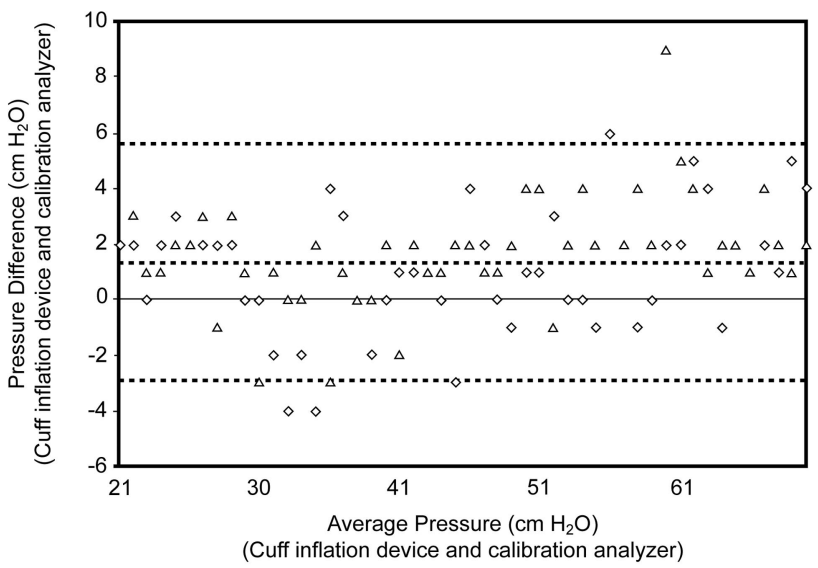

Fig. 4. Analysis of limits of agreement in cuff pressure for 2 cuffinflation devices. The cuff-inflation-device measurements were compared to simultaneously obtained measurements from the calibration analyzer. The open triangles represent the measurements from one of the tested cuff-inflation devices, and the open diamonds represent the measurements from the other cuff-inflation device. The horizontal axis represents the mean of the arithmetic sum of the values measured with the calibration analyzer and the cuff-inflation device. The vertical axis represents the difference between the 2 measurements (calibration analyzer minus cuffinflation device). The grey dashed line represents the mean difference, or bias. The black dotted lines represent the precision ( \pm 2 standard deviations from the mean difference).

\section{Results}

\section{Test 1}

In Part 1 of Test 1 the pressure measured in the cuffinflation device was the same as the pressure measured at the test hub that was delivered by the $3-\mathrm{m}$ cuff-inflation device gas-sampling line. The Pearson correlation was 1.0. In the second Part of Test 1 the cuff-inflation device pressure-gauge display and calibration analyzer comparison mean $\pm \mathrm{SD}$ bias and precision was $1.3 \pm 2.6 \mathrm{~cm} \mathrm{H}_{2} \mathrm{O}$ (Fig. 4).

\section{Test 2}

In Part 1 of Test 2, after $25 \mathrm{~mL}$ of air was injected from the syringe and a 60 -second period for equilibration, the mean $\pm \mathrm{SD}$ bias and precision was $1.3 \pm 2.6 \mathrm{~cm} \mathrm{H}_{2} \mathrm{O}$, or identical results to Test 1. The Pearson correlation was 1.0.

In Part 2 of Test 2 there was no difference in the cuff pressure after adding $5 \mathrm{~mL}$ or $10 \mathrm{~mL}$ of air into the cuff, compared to the baseline cuff pressure from the cuff-inflation device. With the PressureEasy device the cuff pressure increased to a mean of $162 \mathrm{~cm} \mathrm{H}_{2} \mathrm{O}$ after adding $5 \mathrm{~mL}$ of air, and to $301 \mathrm{~cm} \mathrm{H}_{2} \mathrm{O}$ after adding $10 \mathrm{~mL}$ of air. With the syringe-inflation method, cuff pressure increased to a 


\section{Device to Display and Maintain Stable Cuff Pressure}

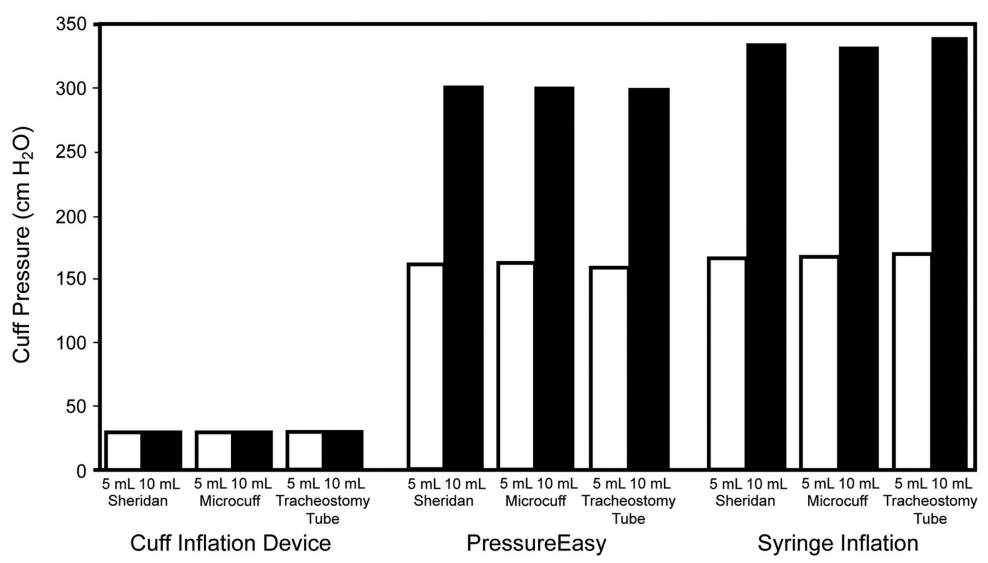

Fig. 5. Cuff-pressure changes after the addition of $5 \mathrm{~mL}$ and $10 \mathrm{~mL}$ of air into the cuff of 3 artificial airways, after initial baseline of $30 \mathrm{~cm} \mathrm{H}_{2} \mathrm{O}$ established. The cuff-inflation device was compared to the PressureEasy device and the syringe-inflation method. The first and second bar in each group represent the cuff pressure (from the calibration analyzer) measured after the additional injection of $5 \mathrm{~mL}$ and $10 \mathrm{~mL}$ of air, with the Sheridan endotracheal tube, the Microcuff endotracheal tube, and the tracheostomy tube.

mean of $167 \mathrm{~cm} \mathrm{H}_{2} \mathrm{O}$ by adding $5 \mathrm{~mL}$ of air, and to $335 \mathrm{~cm} \mathrm{H} \mathrm{H}_{2} \mathrm{O}$ by adding $10 \mathrm{~mL}$ of air (Fig. 5).

\section{Test 3}

The tracheal-cuff seal at different compliance and PEEP levels was analyzed by comparing the measured $\mathrm{V}_{\mathrm{T}}$. The comparison of directly connecting the patient circuit to the test lung was made against inflating the cuffs with the cuff-inflation device and the syringe-inflation method. Compared to the benchmark, the difference in exhaled $\mathrm{V}_{\mathrm{T}}$ mean \pm SD bias and precision were: cuff-inflation device $1.4 \pm 4.8 \mathrm{~mL}$, syringe-inflation method $2.4 \pm 6.2 \mathrm{~mL}$ (Fig. 6).

\section{Test 4}

After disconnecting the ETT pilot balloon from the cuffinflation device gas-sampling line and then reconnecting it, there was no change at 2 seconds or 60 seconds from the baseline cuff pressure. The Pearson correlation was 1.0.

\section{Discussion}

The cuff-inflation device display compared favorably to the calibration analyzer benchmark measurements. The displayed information may increase cuff-pressure awareness as an alternative to the pilot-balloon-palpation and minimal-occlusive-volume techniques, in which pressure is not measured with a manometer. However, without further study and clinical trials, it is unknown whether this information will be beneficial.

Cuff pressure was unchanged from the initial baseline when air was added to the cuff with the cuff-inflation device. This experiment was intended to determine the cuff-inflation device's response to the cuff compression that occurs during daily activities ${ }^{34}$ and the intra-operative cuff diffusion of $\mathrm{N}_{2} \mathrm{O} \cdot{ }^{12,23,24}$ This finding of cuff pressure stability with the cuff-inflation device compares to the syringe-inflation method and the PressureEasy device. With those 2 methods an excessive and unacceptably high pressure was found above their initial baseline inflation (see Fig. 5).

The cuff-inflation device formed an effective seal between the cuff and artificial tracheal wall. This was demonstrated by comparing favorably to the benchmark measurement of exhaled $\mathrm{V}_{\mathrm{T}}$. Finally, when compared to traditional methods used for cuff checks, the cuff pressure was stable after the removal and reconnection of the cuff-inflation device to the pilot balloon. This finding compares to the cuff volume loss that occurs with the devices that are currently used for routine baseline cuff-pressure measurement. ${ }^{30}$

\section{Limitations}

The continuous cuff pressure displayed by the cuff-inflation device suggests that there is a potential for heightening clinician awareness of and adherence to maintaining recommended cuff pressure, but this study does not demonstrate that potential benefit. This study also did not determine whether the findings and inferences made from it are transferable to the clinical setting, or if improvements in outcomes will occur. For example, we do not know if using the cuff-inflation device clinically will prevent secretion leakage past the cuff or otherwise protect against ventilator-associated pneumonia or tracheal injury. Further study is necessary, with a $510 \mathrm{~K}$-approved version of the cuff-inflation device, to determine whether any of the findings from this bench study will be of value or impact clinical outcomes. 


\section{Device to Display and Maintain Stable Cuff Pressure}

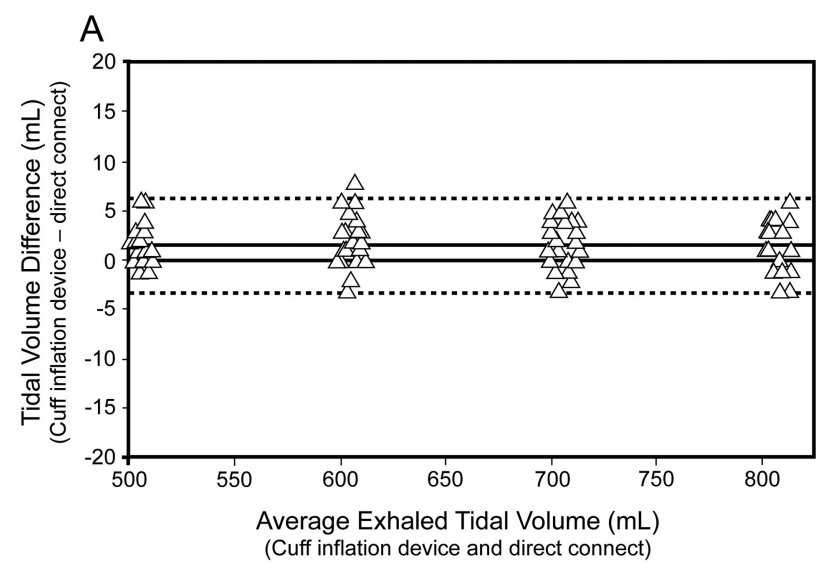

$\mathrm{B}$

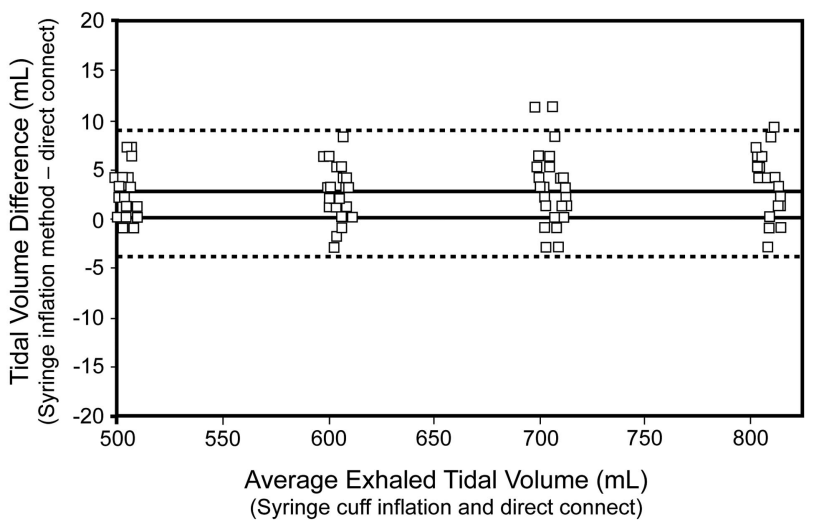

Fig. 6. Analysis of limits of agreement for measurements of exhaled tidal volume with direct patient-circuit connection to the test lung versus cuff inflation of 3 artificial airways with $(A)$ the cuffinflation device (open triangles) and (B) the syringe-inflation method (open squares). The horizontal axis represents the mean of the arithmetic sum of the values of $V_{T}$ measured with $(A)$ direct patient circuit connect and the cuff-inflation device or (B) direct patientcircuit connection and the syringe-inflation method. The vertical axis represents the difference between the 2 measurements $(A$ : calibration analyzer minus cuff-inflation device, and B: calibration analyzer minus syringe-inflation method). The grey solid line represents the mean difference, or bias. The black dotted lines represent the precision ( \pm 2 standard deviations from the mean).

\section{Conclusions}

Artificial airways require vigilant monitoring to ensure that cuff pressure is maintained within an acceptable range. Unfortunately, the existing techniques and devices for monitoring cuff pressure are inadequate. ${ }^{18,20,30}$ Maintaining the cuff pressure is recommended, but in the process of routine checking, the existing techniques and devices substantially lower the cuff volume. We designed a new device to apply continuous cuff pressure, and the device demonstrated a stable, continuous, and accurate display of cuff pressure. As a test of the seal between the cuff and the artificial trachea, the measured exhaled $\mathrm{V}_{\mathrm{T}}$ with the cuff- inflation device compared favorably to the benchmark setup in which the patient circuit was connected directly to the test lung.

We do not know, without further study with a clinically approved version of the cuff-inflation device, if even one ventilator-associated pneumonia or tracheal injury can be prevented. It needs to be determined if clinical benefit will result from cuff-pressure management with a $510 \mathrm{~K}$-approved cuff-inflation device. Further study is warranted if this becomes available, to identify if such a design will have any effect on patient outcomes, compared to the current devices and techniques used for cuff-pressure management.

\section{REFERENCES}

1. Sengupta P, Sessler D, Maglinger P, Wells S, Vogt A, Durrani J, Wadhwa A. Endotracheal tube cuff pressure in three hospitals, and the volume required to produce an appropriate cuff pressure. BMC Anesthesiol 2004;4(1):8.

2. Jaber S, El Kamel M, Chanques G, Sebbane M, Cazottes S, Perrigualt PF, Eledjam JJ. Endotracheal tube cuff pressure in intensive care unit: the need for pressure monitoring. Intensive Care Med 2007;33(5):917-918.

3. Lomholt N. A device for measuring the lateral wall cuff pressure of endotracheal tubes. Acta Anaesthesiol Scand 1992;36(8):775-778.

4. Bernhard WN, Yost L, Joynes D, Cothalis S, Turndorf H. Intracuff pressures in endotracheal and tracheostomy related cuff physical characteristics. Chest 1985;87(6):720-725.

5. Nordin U, Lindholm CE, Wolgast M. Blood flow in the rabbit tracheal mucosa under normal conditions and under influence of tracheal intubation. Acta Anaesthesiol Scand 1977;21(2):81-94.

6. Seegobin RD, van Hasselt GL. Endotracheal cuff pressure and tracheal mucosal blood flow: endoscopic study of effects of four large volume cuffs. Br Med J (Clin Res Ed) 1984;288(6422):965-968.

7. Nseir S, Brisson H, Marquette C, Chaud P, Di Pompeo C, Diarra M, Durocher A. Variations in endotracheal cuff pressure in intubated critically ill patients: prevalence and risk factors. E J Anaesth 2009; 26(3):229-234

8. Feldman C, Kassel M, Cantrell J, Kaka S, Morar R, Goolam M Philips J. The presence and sequence of endotracheal tube colonization in patients undergoing mechanical ventilation. Eur Respir $\mathrm{J}$ 1999;13(3):546-551.

9. Zur K, Mandell D, Gordon R, Holzman I, Rothschild M. Electron microscopic analysis of biofilm on endotracheal tubes removed from intubated neonates. Otolaryngol Head Neck Surg 2004;130(4):407414.

10. Brook I. Role of anaerobic bacteria in infections following tracheostomy, intubation, or the use of ventilatory tubes in children. Ann Otol Rhinol Laryngol 2004;113(10):830-834.

11. Asai T, Shingu K. Leakage of fluid around high-volume, low-pressure cuffs apparatus a comparison of four tracheal tubes. Anaesthesia 2001;56(1):38-42.

12. al-Shaikh B, Jones M, Baldwin F. Evaluation of pressure changes in a new design tracheal tube cuff, the Portex Soft Seal, during nitrous oxide anaesthesia. Br J Anaesth 1999;83(5):805-806.

13. Combes X, Schauvliege F, Peyrouset O, Motamed C, Kirov K, Dhonneur G, Duvaldestin P. Intracuff pressure and tracheal morbidity: influence of filling with saline during nitrous oxide anesthesia. Anesthesiology 2001;95(5):1120-1124.

14. Vyas D, Inweregbu K, Pittard A. Measurement of tracheal tube cuff pressure in critical care. Anaesthesia 2002;57(3):275-277. 


\section{Device to Display and Maintain Stable Cuff Pressure}

15. Fernandez R, Blanch L, Mancebo J, Bonsoms N, Artigas A. Endotracheal tube cuff pressure assessment: pitfalls of finger estimation and need for objective measurement. Crit Car Med 1990;18:14231426.

16. Stewart SL, Secrest JA, Norwood BR, Zachary R. A comparison of endotracheal tube cuff pressures using estimation techniques and direct intracuff measurement. AANA J 2003;71:443-447.

17. Zand F, Nekooeian A, Rohani M. Endotracheal tube cuff pressure monitoring in intensive care units. IRCMJ 2008;10(3):223-227.

18. Faris C, Koury E, Philpott J, Sharma S, Tolley N, Narula A. Estimation of tracheostomy tube cuff pressure by pilot balloon palpation. J Laryngol Otol 2007;121(9):869-871.

19. Morris L, Zoumalan R, Roccaforte J, Amin M. Monitoring tracheal tube cuff pressures in the intensive care unit: a comparison of digital palpation and manometry. Ann Otol Rhinol Laryngol 2007;116(9): 639-642.

20. Rose L, Redl L. Survey of cuff management practices in intensive care units in Australia and New Zealand. Am J Crit Care 2008;17(5): 428-435.

21. American Association for Respiratory Care. AARC Clinical Practice Guideline. Patient-ventilator system checks. Respir Care 1992;37(8): 882-886.

22. Sole ML, Byers JF, Ludy JE, Zhang Y, Banta CM, Brummel K. A multisite survey of suctioning techniques and airway management practices. Am J Crit Care 2003;12:220-230.

23. Tu H, Saidi N, Leiutaud T, Bensaid S, Menival V, Duvaldestin P. Nitrous oxide increases endotracheal cuff pressure and the incidence of tracheal lesions in anesthetized patients. Anesth Analg 1999;89(1): 187-190.

24. Braz J, Volney A, Navarro L, Braz L, Nakamura G. Does sealing endotracheal tube cuff pressure diminish the frequency of postoperative laryngotracheal complaints after nitrous oxide anesthesia? J Clin Anesth 2004;16(5):320-325.
25. Galinski M, Tréoux V, Garrigue B, Lapostolle F, Borron S, Adnet F. Intracuff pressures of endotracheal tubes in the management of airway emergencies: the need for pressure monitoring. Ann Emerg Med 2006; 47(6):545-547.

26. Mann C, Parkinson N, Bleetman A. Endotracheal tube and laryngeal mask airway cuff volume changes with altitude: a rule of thumb for aeromedical transport. Emerg Med J 2007;24(3):165-167.

27. Pneumatikos I, Dragoumanis C, Bouros D. Ventilator-associated pneumonia or endotracheal tube-associated pneumonia? An approach to the pathogenesis and preventive strategies emphasizing the importance of endotracheal tube. Anesthesiology 2009;110(3): 673-680.

28. Felten M-L, Schmautz E, Delaporte-Cerceau S, Orliaguet G, Carli P. Endotracheal tube cuff pressure is unpredictable in children. Anesth Analg 2003;97(6):1612-1616.

29. Karasawa F, Mori T, Kawatani Y, Ohshima T, Satoh T. Deflationary phenomenon of the nitrous oxide-filled endotracheal tube cuff after cessation of nitrous oxide administration. Anesth Analg 2001;92(1): 145-148.

30. Blanch P. Laboratory evaluation of 4 brands of endotracheal tube cuff inflator. Respir Care 2004;49(2):166-173.

31. Rose L, Redl L. Minimal occlusive volume cuff inflation: a survey of current practice. Intensive Crit Care Nurs 2008;24(6):359-365.

32. American Thoracic Society; Infectious Diseases Society of America. Guidelines for the management of adults with hospital-acquired, ventilator-associated, and healthcare-associated pneumonia. Am J Respir Crit Care Med 2005;171(4):388-416.

33. Bland J, Altman D. Statistical methods for assessing agreement between two methods of clinical measurement. Lancet 1986;1(8476):307-310.

34. Sole ML, Aragon-Penoyer D, Su X, Jimenez E, Kalita S, Poalillo E, et al. Assessment of endotracheal cuff pressure by continuous monitoring: a pilot study. Am J Crit Care 2009;18(2):133-143.

This article is approved for Continuing Respiratory Care Education credit. For information and to obtain your CRCE

(free to AARC members) visit wWw.RCJournal.com

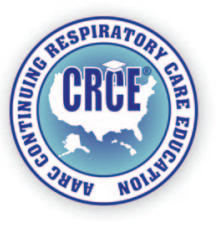

